\title{
Risky Sex and HIV Acquisition Among HIV Serodiscordant Couples in Zambia, 2002-2012: What Does Alcohol Have To Do With It?
}

\author{
Dvora Joseph Davey ${ }^{1,3,10} \cdot$ William Kilembe ${ }^{1,2} \cdot K_{\text {Kristin M. Wall }}^{1,2,4}$ • \\ Naw Htee Khu ${ }^{1,2} \cdot$ Ilene Brill ${ }^{1,2,5} \cdot$ Bellington Vwalika ${ }^{1,2,8} \cdot$ Elwyn Chomba $^{6}$. \\ Joseph Mulenga $^{1,2,9} \cdot$ Amanda Tichacek $^{1,2} \cdot$ Marjan Javanbakht $^{3} \cdot$ W. Scott Comulada ${ }^{7}$. \\ Susan Allen ${ }^{1,2} \cdot$ Pamina M. Gorbach ${ }^{3}$
}

Published online: 27 February 2017

(C) Springer Science+Business Media New York 2017

\begin{abstract}
In this paper we evaluate the effects of heavy alcohol consumption on sexual behavior, HIV acquisition, and antiretroviral treatment (ART) initiation in a longitudinal open cohort of 1929 serodiscordant couples in Lusaka, Zambia from 2002 to 2012. We evaluated factors associated with baseline heavy alcohol consumption and its association with condomless sex with the study partner, sex outside of the partnership, and ART initiation using multivariable logistic regression. We estimated the effect of
\end{abstract}

Dvora Joseph Davey

dvoradavey@ucla.edu; djosephdavey@mednet.ucla.edu

1 Rwanda Zambia HIV Research Group (RZHRG), Department of Pathology \& Laboratory Medicine, School of Medicine, Emory University, Atlanta, GA, USA

2 Hubert Department of Global Health, Rollins School of Public Health, Emory University, Atlanta, GA, USA

3 Department of Epidemiology, Fielding School of Public Health, University of California, Los Angeles, 650 Charles E. Young Drive South, Los Angeles, CA 90095, USA

4 Department of Epidemiology, Rollins School of Public Health, Laney Graduate School, Emory University, Atlanta, GA, USA

5 Department of Epidemiology, Ryals School of Public Health, University of Alabama at Birmingham, Birmingham, AL, USA

6 School of Medicine, University of Zambia, Lusaka, Zambia

7 Department of Psychology, University of California, Los Angeles, Los Angeles, CA, USA

8 Department of Obstetrics and Gynecology, University of Zambia, Lusaka, Zambia

9 Zambia National Blood Transfusion Service, Lusaka, Zambia

10 Centre for Infectious Disease Epidemiology and Research, University of Cape Town, Cape Town, South Africa alcohol consumption on HIV acquisition using multivariable Cox models. Baseline factors significantly associated with women's heavy drinking (drunk weekly or more in 12-months before enrollment) included woman's older age (adjusted prevalence odds ratio $[\mathrm{aPOR}]=1.04$ ), partner heavy drinking $(\mathrm{aPOR}=3.93$ ), and being HIV-infected $(\mathrm{aPOR}=2.03)$. Heavy drinking among men was associated with less age disparity with partner (aPOR per year disparity $=0.97)$ and partner heavy drinking (aPOR $=$ 1.63). Men's being drunk daily $(\mathrm{aOR}=1.18)$, women's being drunk less than monthly $(\mathrm{aOR}=1.39)$ vs. never drunk and being in a male HIV-negative and female HIVpositive union $(\mathrm{aOR}=1.45)$ were associated with condomless sex. Heavy alcohol use was associated with having 1 or more outside sex partners among men (aOR drunk daily $=1.91$, drunk weekly $=1.32$, drunk monthly $=2.03$ vs. never), and women (aOR drunk monthly $=2.75$ vs. never). Being drunk weekly or more increased men's risk of HIV acquisition (adjusted hazard ratio [aHR] $=1.72$ ). Men and women being drunk weekly or more was associated $(p<0.1) \quad$ with women's seroconversion (aHR $=1.42$ and aHR $=3.71$ respectively). HIV-positive women who were drunk monthly or more had lower odds of initiating ART $(\mathrm{aOR}=0.83 ; 95 \% \mathrm{CI}=0.70-0.99)$ adjusting for age, months since baseline and previous pregnancies. Individuals in $\mathrm{HIV}$-serodiscordant couples who reported heavy drinking had more outside sex partnerships and condomless sex with their study partner and were more likely to acquire HIV. HIV-positive women had lower odds of initiating ART if they were heavy drinkers.

Resumen Nuestro estudio evaluó los efectos del consumo de alcohol en el comportamiento sexual, la adquisición del VIH y la iniciación del tratamiento antirretroviral (TARV) en una cohorte de 1929 parejas serodiscordantes en 
Zambia. Los factores asociados con el consumo intensivo de alcohol de las mujeres (bebido semanalmente o más de 12 meses antes de la inscripción) incluyeron la edad avanzada, el consumo excesivo de alcohol de pareja y la infección por el VIH. El consumo excesivo de alcohol entre los hombres también se asoció con el consumo excesivo de alcohol de las mujeres. Los hombres que se emborrachan diariamente, las mujeres se emborrachan menos de una vez al mes vs. nunca se asocian con sexo sin condón. El consumo excesivo de bebidas alcohólicas se asoció con tener más de 1 pareja entre hombres y mujeres. Estar ebrio semanalmente o aumentar el riesgo de los hombres de la adquisición de VIH (aHR = 1.72). Los hombres y las mujeres que se emborrachaban semanalmente o más se asociaron $(\mathrm{p}<0.1)$ con la seroconversión de las mujeres $(\mathrm{aHR}=1.42$ y aHR $=3.71$ respectivamente). Las mujeres infectadas por el VIH bebían mensualmente o más tenían probabilidades más bajas de iniciar el TARV $(\mathrm{aOR}=0.83 ; 95 \% \mathrm{CI}=0.70-0.99)$ ajustándose a los confounders. Los individuos de parejas serodiscordantes con VIH que reportaron tener un consumo excesivo de alcohol tuvieron más asociaciones externas y sexo sin condón y fueron más propensos a contraer el VIH. Las mujeres que reportaron tener un consumo excesivo de alcohol iniciación menos el TARV.

Keywords Alcohol use - Sexual behavior · HIV serodiscordant couples · HIV transmission - Zambia

\section{Introduction}

Despite the decline in HIV incidence, sub-Saharan Africa remains disproportionately affected with $70 \%$ of all incident HIV infections [1]. HIV prevalence within sub-Saharan Africa varies by region as does the prevalence of HIV serodiscordant couples, in which one partner is HIV-infected $(\mathrm{HIV}+)$, and the other HIV-uninfected (HIV-). The prevalence of HIV among in Zambia is $14.3 \%$ overall, and is higher among females than males (16.1 vs. $12.3 \%$ respectively) [1]. Up to two-thirds of HIV+ African adults in a cohabiting relationship have an HIV - partner [2-4], and women are as likely as men to be the HIV+ member in a serodiscordant couple [4]. HIV incidence in serodiscordant couples ranges from 2.0 to 10.2 per 100 person-years depending on the type of study, and accompanying services made available to the couples such as couples' HIV counseling and testing, antiretroviral therapy (ART), pre-exposure prophylaxis (PrEP), male circumcision, and condom provision [2, 4].

Though joint HIV counseling and testing reduces risk behavior and HIV incidence, residual HIV transmission continues to occur in the context of stable HIV serodiscordant heterosexual relationships [2-5]. The high prevalence of serodiscordant couples [2, 3], combined with the high risk of HIV acquisition and transmission within those relationships in couples makes serodiscordant couples an important target for HIV prevention efforts across East and Southern Africa [3, 4].

Heavy alcohol use is a widespread problem among those at risk for and living with HIV, and its use by at least one partner can affect HIV transmission and acquisition risk to both partners [6-10]. Alcohol elevates sexual risks through its effect on personality and its influence on decisionmaking [7, 9, 10]. Further, excess alcohol consumption may lead to immune deficiency, causing increased susceptibility to opportunistic infections [11]. Alcohol use is a major health risk factor in Zambian men. According to the Zambian Demographic Health Survey, $9.8 \%$ of male drinkers reported heavy episodic drinking, defined as consuming $\geq 60$ grams of pure alcohol on at least one occasion in the past 30-days [12]. Further, a 2013 study demonstrated that the prevalence of alcohol dependence was high in those infected with TB and HIV (27.2\% among men, and 3.9\% among women) [12].

A number of studies have shown a consistent association between alcohol use and risk behaviors. A 2011 Ugandan study found associations between alcohol use, increased extramarital sex, condomless sex, and HIV transmission [9]. A recent meta-analysis demonstrated that alcohol consumption was associated with greater intentions to engage in condomless sex, highlighting the need for continued research on the impact of alcohol on HIV and sexually transmitted infection (STI) transmission, especially among women, who have rarely been a focus of such studies [10]. Alcohol use has been associated with HIV progression and impaired inflammatory response, and poorer ART adherence in Africa [10, 13]. A recent study in the US showed that untreated HIV infection was associated with higher blood alcohol levels [13], however the role of alcohol consumption on ART initiation has not been explored. A previous study in the same Zambian cohort as our analyses for this paper [7] showed that alcohol use by male partners of serodiscordant couples was associated with condomless sex with their primary partner during study follow-up. However, that analysis lacked the power to detect differences between men and women's alcohol use, HIV incidence or ART initiation and was limited to early cohort enrollment through 2007 including fewer than 1000 couples.

There is a paucity of evidence about the relationship between heavy alcohol use and HIV risk factors and transmission in African women, and within couples in particular [12-14]. Our study evaluated factors associated with heavy alcohol consumption in men and women in cohabiting heterosexual discordant couples in Lusaka, Zambia from 2002 until 2012. We then examined the role of heavy alcohol consumption on risky sexual behavior, 
HIV acquisition, and ART initiation after joint HIV testing and counseling.

\section{Methods}

The Heterosexual Transmission of HIV Study was an open prospective cohort which enrolled adult heterosexual serodiscordant couples recruited from couples' voluntary counseling and testing (CVCT) centers in Lusaka, Zambia. Data collection began February 1995 and ended December 2012. Our analysis for this study was limited to couples enrolled from 2002 to 2012, when detailed data on alcohol use was routinely collected. The study was approved by Office for Human Research Protections-registered IRBs at Emory University and at the University of Zambia. Joint written informed consent was obtained from all participating couples.

\section{Study Participants}

Legally or traditionally married or cohabiting couples in Lusaka, Zambia attended CVCT services spontaneously or after receiving an invitation from a community promoter $[3,14]$. Couples came into couple's HIV counselling and testing together voluntarily. During pre-test counselling the counsellor would confirm the voluntary nature of the CVCT services with each partner to ensure that neither partner has been coerced to get tested with their partner. CVCT services included a group counseling session followed by rapid HIV testing, and joint post-test couples' counseling [2, 3].

During the study period (1995-2012), availability of couples voluntary counselling and testing services evolved: between 1995 and 2002, there were two locations for CVCT in Lusaka as recruitment tools for the discordant couple cohort [3, 15]. From 2003 to 2007, we evaluated the optimal procedures for promoting and providing CVCT as an HIV prevention intervention [14]. From 2007 to 2012, the Centers for Disease Control (CDC) established CVCT services in Lusaka government clinics. In 2007, CDC guidelines for training CVCT counsellors were posted on the CDC website (https://www.cdc.gov/globalaids/resour ces/prevention/chct-training.html). Typically, HIV counselling and testing is provided to individuals alone, not couples together. This importance of CVCT is now recognized following publication of World Health Organization guidelines in 2012 (http://www.who.int/hiv/pub/ guidelines/9789241501972/en/). In all CVCT service points, eligible discordant couples were given invitations to enroll in the cohort study, which provided ongoing counselling, access to male and female condoms, STI screening, and referral services for HIV care and treatment, as well male circumcision services for HIV - men.
Previous studies have demonstrated that clinic and community-based CVCT promotions can increase CVCT awareness and demand [3, 14]. We conducted promotional efforts, including personal invitations in the community which were provided by influential network leaders (INLs) and agents (INAs), based on the Social Networks and Social Support Theory. We report on the specifics of the intervention elsewhere [14]. Briefly, INLs were identified from city meetings and referrals from four social networks (faith-based/religious, health, private and communitybased/non-governmental organizations). INLs identified INA candidates from their respective networks, and final selection was made after interviewing with experienced counsellors. Enrolled INAs received 4-day training in HIV health advocacy/outreach, social networking, CVCT promotions and observation of successful door-to-door promotional strategies. Our research found that social networks and community leaders are critical in changing perceptions towards CVCT and increasing demand for CVCT in Zambia [14].

Study eligibility criteria included: (1) confirmed HIV-1 serodiscordance (one partner confirmed serologically $\mathrm{HIV}+$ and one partner confirmed serologically HIV-), (2) being married or cohabiting for at least 3-months, and (3) planning on staying in the Lusaka area for the next year. Couples were ineligible if the HIV+ partner was on ART, which was introduced in government clinics in 2007. Couples were censored if either partner died, the couple separated, the HIV+ partner initiated ART, or if either partner was lost to follow-up.

\section{Data Collection}

Study participants had quarterly visits and access to outpatient care at any time, including during routine visits. At baseline, study participants completed behavioral (including an alcohol assessment) and medical history questionnaires, and had a physical examination including genital exams, as well as HIV and STI screening. Quarterly follow-up visits included a physical exam (including STI testing if symptoms were present and treatment according to national guidelines), a blood sample for HIV testing (HIV - partner), a vaginal swab wet mount, and completion of study questionnaires, comprising questions on demographic, psychosocial, behavioral, medical history, and health services data. Quarterly, study participants were asked to report on their behavior in the 3-months before their study appointment. Questionnaire data was collected through face-to-face interview between counselors/nurses and individual participants (couples were separated for the interviews) and had been translated into the local languages Nyanja and Bemba. Each partner's response to sexual 
behavior questions within the union were cross referenced with their partner's response.

\section{HIV Testing}

HIV testing of HIV - partners was conducted using a rapid serologic test [16]. To determine time of incident infection, beginning in 2003, when possible plasma from the last antibody negative sample was tested with p24 antigen ELISA and RNA polymerase chain reaction. Comparison of conserved PCR-amplified nucleotide sequences from each member of the couple classified incident infections as linked to the study partner or unlinked (acquired from outside the study couple) [17]. Our analysis includes both linked and unlinked seroconversion.

\section{Alcohol Use}

Beginning in 2002, data on alcohol consumption was collected at baseline using a shortened version of the Alcohol Use Disorders Identification Test tool (AUDIT) [18], which includes questions on frequency and quantity of alcohol drinking, and anyone asking them to cut down on drinking in the past. We shortened the AUDIT tool to include 4 of the 10 questions around alcohol use including: (1) In the last year, (prior to study enrollment), how often did you have a drink containing alcohol? (2) "In the last year (prior to study enrollment), how often did you get drunk?" Responses included: never, less than monthly, monthly, weekly, daily/almost daily, (3) How long ago did you have your last drink? Responses were given in months. (4) Has a relative or friend or a doctor or other health worker, been concerned about your drinking or suggested that you cut down? Because Question 3 on last drink was collected in months, it was not sensitive enough to be associated with any outcomes in our study so it as not included in the final analyses.

\section{Analyses}

We included 1929 couples in our analysis which reported data on alcohol use of which 1125 were Man HIV-/Woman $\mathrm{HIV}+(\mathrm{M}-\mathrm{F}+)$, and 804 were Man HIV+/Woman HIV - $(\mathrm{M}+\mathrm{F}-)$ couples. We present the distribution of frequency of drunkenness stratified by gender and HIV status. Demographic and behavioral data are related to alcohol consumption (reporting being drunk weekly or more frequently, versus being drunk less than weekly or never in the past year at baseline) with counts and percentages (for categorical variables), or means and standard deviations (for continuous variables). We analyze these baseline factors associated with the outcome of heavy drinking in the year prior to baseline, stratified by gender using multivariable logistic regression, adjusting for a priori confounders. To test the hypothesis that there is a dose-response between increasing alcohol use and association with sexual behaviors and HIV acquisition, we analyze the effect of all levels of alcohol consumption at baseline as a categorical variable on the subsequent outcomes of condomless sex with the study partner and sex with outside partner(s) during the study (these variables were collected at each study visit) using multivariable logistic regression, adjusting for months since baseline, and a priori confounders (age, HIV status, and years cohabiting).

We then analyzed the effect of heavy alcohol consumption on HIV acquisition with multivariable Cox survival models to evaluate the relationship between heavy alcohol use (drunk weekly, daily or almost daily vs. drunk less than weekly or never) and time to seroconversion by gender of seroconverter adjusting for a priori confounders (age, literacy, years cohabiting, number of previous pregnancies, and male circumcision) from previous literature $[2,4,5,7,9,11])$. The proportional hazards assumption was tested for time-independent covariates using KaplanMeier curves [19]. Finally, we specified logistic regression models from 2007 (when ART became widely available) to 2012 to evaluate the impact of heavy alcohol use on ART initiation, adjusting for months since baseline and a priori confounders (age and literacy). We evaluated the presence of effect-measure modification for gender of the HIV+ partner in each model. Multi-collinearity was assessed by analyzing the variance inflation factor and tolerance to check the degree of collinearity between variables. All analyses were conducted with SAS v9.4 (Cary, NC).

\section{Results}

\section{Descriptive Analyses of Drinking Patterns}

Men reported drinking alcohol more frequently than women, with approximately $21 \%$ of women reported drinking alcohol in the year before couples testing and study enrollment, compared to $69 \%$ of men: $17 \%$ of men and $2 \%$ of women reported drinking alcohol $\geq 4$ times a week, and $8 \%$ of men and $1 \%$ of women reported being drunk daily or almost daily. Approximately $6 \%$ of women, and $33 \%$ of men reported that in the past year, a relative, friend or health care provider suggested that they cut down on drinking (not tabled) (Fig. 1).

In $\mathrm{M}+\mathrm{F}-$ couples, $37 \%$ of men reported getting drunk weekly, and $13 \%$ reported getting drunk daily or almost daily $(\mathrm{n}=402)$, whereas $2 \%$ of women reported getting drunk weekly, and $1 \%$ getting drunk daily or almost daily 

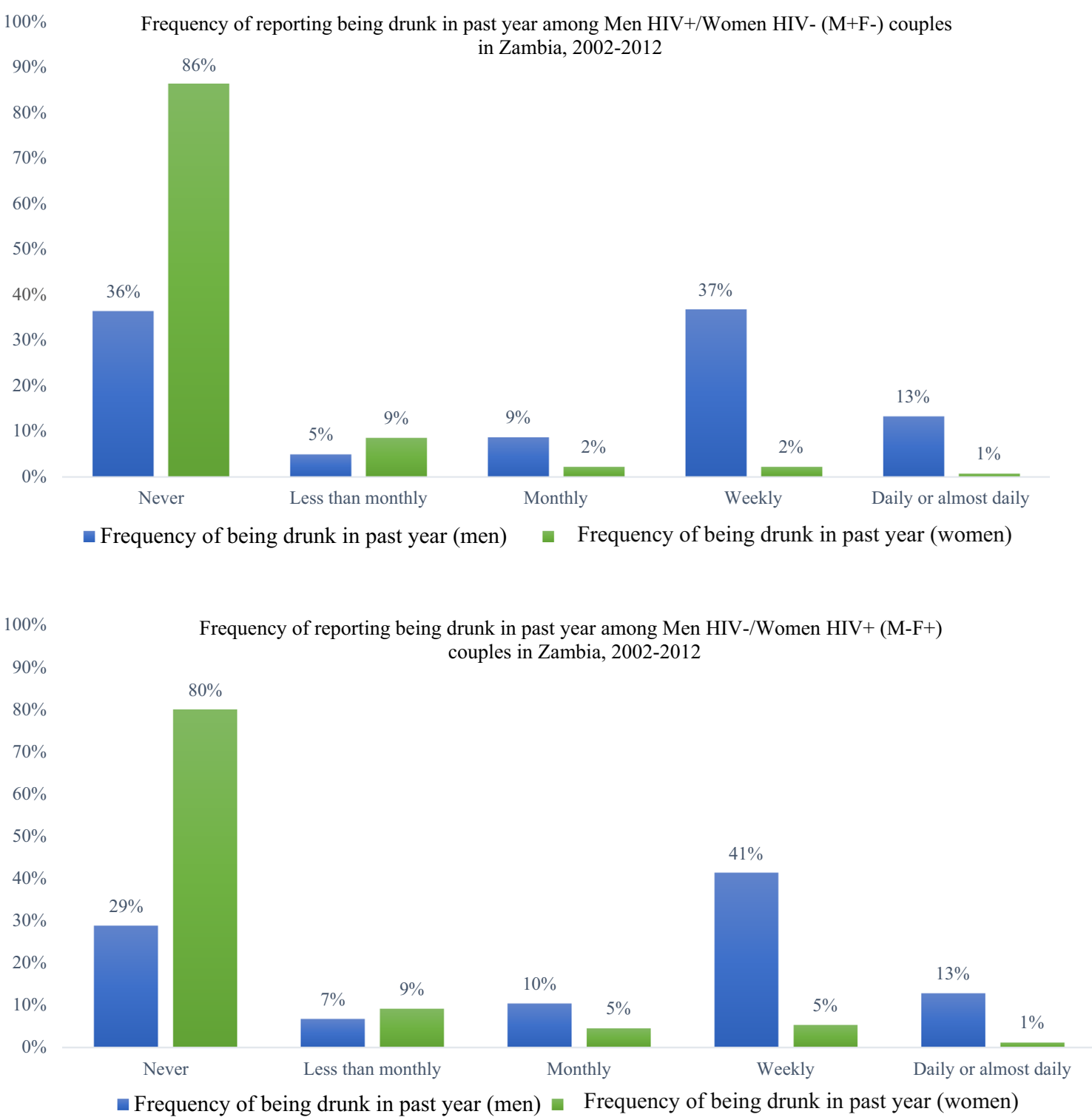

Fig. 1 Frequency of reporting being drunk in the past year at baseline by serostatus of couple $(\mathrm{n}=804$ Men HIV+/women HIV-, and 1125 Men HIV-/Women HIV+ couples)

$(\mathrm{n}=24)$. Similarly, in $\mathrm{M}-\mathrm{F}+$ couples, $41 \%$ of men reported getting drunk weekly, and $13 \%$ reported getting drunk daily or almost daily $(\mathrm{n}=608)$, whereas $5 \%$ of women reported getting drunk weekly, and $1 \%$ getting drunk daily or almost daily $(\mathrm{n}=73)$.

\section{Demographic and Behavioral Characteristics by Heavy Alcohol Use}

Overall, $57 \%$ of couples had at least 1 year of follow-up, $35 \%$ had $\geq 2$ years, and $22 \%$ had $\geq 3$ years (mean followup was 616 days or 1.7 years per couple) and did not differ by reported alcohol use. Women who reported being drunk weekly or more were slightly older (30.5 vs. 29.2 mean years old), were closer in age to their partners (5.6 vs. 6.7years' difference), had a greater proportion of partners who also reported heavy drinking (defined as drunk weekly or more in 12 -months before enrollment) (75 vs. $51 \%$ ), had fewer live children (1.1 vs. 1.8$)$ and were more often $\mathrm{HIV}+$ than moderate/non-drinkers (75 vs. $57 \%$ ). Women self-reporting having a STI in the last year was higher among heavy drinkers (38 vs. $27 \%$ ). Heavy drinkers had about the same proportion of intervals in which they reported condomless sex during follow-up (31 vs. 30\%), and reported having an outside partner slightly more than moderate/non-drinkers (2 vs. $1 \%$ ) (Table 1 ).

Men who were heavy drinkers were slightly younger (35.1 vs. 36.1 mean years old), were closer in age with their 
Table 1 Demographic and behavioral characteristics by women's alcohol use, 2002-2012

\begin{tabular}{|c|c|c|c|c|c|}
\hline \multirow[b]{2}{*}{ Total } & \multirow{2}{*}{$\begin{array}{c}\text { Total } \\
\mathbf{1 9 2 9}\end{array}$} & \multicolumn{2}{|c|}{$\begin{array}{l}\text { Heavy drinkers (reported } \\
\text { being drunk weekly or } \\
\text { more frequently in the } \\
\text { past year) }\end{array}$} & \multicolumn{2}{|c|}{$\begin{array}{l}\text { Moderate/no drinkers } \\
\text { (reported being drunk } \\
\text { less than weekly or never } \\
\text { in the past year) }\end{array}$} \\
\hline & & 97 & $5 \%$ & 1832 & $95 \%$ \\
\hline \multicolumn{6}{|l|}{ Demographics } \\
\hline Study follow up time in days (mean, SD) & $615.9(597.2)$ & 613.2 & 562.5 & 615.8 & 599.1 \\
\hline Women's age (mean, SD)** & $28.5(6.8)$ & 30.5 & 6.0 & 29.2 & 6.5 \\
\hline Age difference in years (mean, SD)* & $6.6(4.6)$ & 5.6 & 4.9 & 6.7 & 4.6 \\
\hline Years cohabiting (mean, SD) & $6.9(6.1)$ & 5.8 & 5.8 & 7.0 & 6.1 \\
\hline Monthly family income USD (mean, SD) & $110.4(128.9)$ & 113.3 & 154.9 & 108.8 & 127.1 \\
\hline \multicolumn{6}{|l|}{ Women read Nyanja } \\
\hline Yes, easily & $501(26 \%)$ & 23 & $24 \%$ & 478 & $26 \%$ \\
\hline With difficulty/not at all & $1423(74 \%)$ & 74 & $76 \%$ & 1349 & $74 \%$ \\
\hline Partner reported heavy drinking (drunk weekly or more frequently)** & $1006(52 \%)$ & 73 & $75 \%$ & 933 & $51 \%$ \\
\hline \multicolumn{6}{|l|}{ Baseline sexual history } \\
\hline Women \# of sex partners in last year (mean, SD) & $1.1(0.9)$ & 1.4 & 0.9 & 1.1 & 1.0 \\
\hline \# of live children (mean, SD)* & $1.7(1.6)$ & 1.1 & 1.3 & 1.8 & 1.7 \\
\hline Women self-report STI last year** & $533(28 \%)$ & 37 & $38 \%$ & 496 & $27 \%$ \\
\hline \multicolumn{6}{|l|}{ Baseline clinical } \\
\hline Woman HIV+/Man HIV-** & $1126(58 \%)$ & 73 & $75 \%$ & 1053 & $57 \%$ \\
\hline Log viral load HIV+ partner, $\log 10$ copies (mean, SD) & $4.6(0.9)$ & 4.7 & 1.2 & 4.4 & 1.0 \\
\hline \multicolumn{6}{|l|}{ Behavioral (time-varying, $\mathrm{n}=$ intervals) } \\
\hline Condomless sex with partner during study & $4526(30 \%)$ & 203 & $31 \%$ & 4323 & $30 \%$ \\
\hline Sex with another partner & $179(1 \%)$ & 12 & $2 \%$ & 167 & $1 \%$ \\
\hline
\end{tabular}

Frequencies not equal to total $\mathrm{N}$ due to missing data

STI sexually transmitted infection, USD United States Dollar, $S D$ standard deviation

$* \mathrm{p}<0.05 ; * * \mathrm{p}<0.01$

partners (6.2 vs. 7.1 years' difference), had a greater proportion had female partners who reported heavy drinking (12 vs. 5\%), reported more STIs in the past year (33 vs. $29 \%$ ), and had more sex partners in the past year (1.7 vs. 1.6). Heavy drinkers had about the same proportion of intervals in which they reported condomless sex during follow-up (30 vs. 29\%), and reported the same proportion of having an outside partner (6 vs. 5\%) (Table 2).

\section{Factors Independently Associated with Women Reporting Heavy Alcohol Use}

Women's older age (adjusted prevalence odds ratio $[\mathrm{aPOR}]=1.04,95 \% \mathrm{CI}=1.00,1.09)$, partner who reported heavy drinking $(\mathrm{aPOR}=3.93,95 \% \mathrm{CI}=1.94$, 7.17), HIV status (woman HIV+ at baseline $\mathrm{aPOR}=2.03,95 \% \mathrm{CI}=1.12,3.67)$ were associated with heavy alcohol consumption adjusting for age disparity with partner, and number of live children.

\section{Factors Independently Associated With Men Reporting} Heavy Alcohol Use

Lower age disparity with partner $(\mathrm{aPOR}=0.97,95 \%$ $\mathrm{CI}=0.94,0.99)$ and having a partner who reported heavy drinking $\quad(\mathrm{aPOR}=1.63,95 \% \quad \mathrm{CI}=1.35,1.96)$ were associated with men's heavy drinking adjusting for men's age, years cohabiting, literacy, number of sex partner and self-reported STI in the past year (Table 3).

\section{Alcohol Association With Condomless Sex With Partner}

Given the lack of association between weekly drunkenness, outside partners and condomless sex in the bivariate analysis, we used a categorical variable to examine possible dose-response relationships in a multivariate analysis. Controlling for age, years cohabiting, months since baseline, and HIV status, men who reported being drunk daily or almost daily had increased odds of having condomless 
Table 2 Demographic and behavioral characteristics by men's alcohol use, 2002-2012

\begin{tabular}{|c|c|c|c|c|c|}
\hline \multirow[b]{2}{*}{ Total } & \multirow{2}{*}{$\begin{array}{l}\text { Total } \\
\mathbf{1 9 2 9}\end{array}$} & \multicolumn{2}{|c|}{$\begin{array}{l}\text { Heavy drinkers (reported } \\
\text { being drunk weekly or } \\
\text { more frequently in the } \\
\text { past year) }\end{array}$} & \multicolumn{2}{|c|}{$\begin{array}{l}\text { Moderate/no drinkers } \\
\text { (reported being drunk } \\
\text { less than weekly or never } \\
\text { in the past year) }\end{array}$} \\
\hline & & 1010 & $52 \%$ & 919 & $48 \%$ \\
\hline \multicolumn{6}{|l|}{ Demographics } \\
\hline Study follow up time (days, mean, SD) & $615.9(597.2)$ & 610.0 & 574.5 & 621.2 & 620.8 \\
\hline Men's age $($ mean, $S D) * *$ & $35.5(7.7)$ & 35.1 & 7.0 & 36.1 & 8.3 \\
\hline Age difference in years (mean, SD)** & $6.6(4.6)$ & 6.2 & 4.4 & 7.1 & 4.7 \\
\hline Years cohabiting (mean, SD) & $6.9(6.1)$ & 6.8 & 5.8 & 7.1 & 6.4 \\
\hline Monthly family income USD (mean, SD) & $110.4(128.9)$ & 101.7 & 109.4 & 118.8 & 145.5 \\
\hline \multicolumn{6}{|l|}{ Men read Nyanja } \\
\hline Yes, easily & $869(45 \%)$ & 435 & $43 \%$ & 434 & $47 \%$ \\
\hline With difficulty/not at all & $1057(55 \%)$ & 574 & $57 \%$ & 483 & $53 \%$ \\
\hline Partner reported heavy drinking (drunk weekly or more frequently) ${ }^{* *}$ & $166(9 \%)$ & 121 & $12 \%$ & 45 & $5 \%$ \\
\hline \multicolumn{6}{|l|}{ Baseline sexual history } \\
\hline Men \# of sex partners last year (mean, SD)* & $1.7(1.7)$ & 1.7 & 1.4 & 1.6 & 1.6 \\
\hline Men history of STI last year* & $596(31 \%)$ & 332 & $33 \%$ & 264 & $29 \%$ \\
\hline \multicolumn{6}{|l|}{ Baseline clinical } \\
\hline Man HIV+/Woman HIV- & $805(42 \%)$ & 402 & $40 \%$ & 402 & $43 \%$ \\
\hline Log viral load HIV+ partner, $\log 10$ copies (mean, SD)* & $4.4(1.0)$ & 4.4 & 1.1 & 4.4 & 1.0 \\
\hline \multicolumn{6}{|l|}{ Behavioral (time-varying, $\mathrm{n}=$ intervals) } \\
\hline Condomless sex with partner during study & $4886(30 \%)$ & 2572 & $30 \%$ & 2314 & $29 \%$ \\
\hline Sex with another partner during study & $720(5 \%)$ & 417 & $6 \%$ & 303 & $5 \%$ \\
\hline
\end{tabular}

Frequencies not equal to total $\mathrm{N}$ due to missing data

STI sexually transmitted infection, USD United States Dollar, $S D$ standard deviation

$* \mathrm{p}<0.05 ; * * \mathrm{p}<0.01$

sex with their study partner $(\mathrm{aOR}=1.18,95 \% \mathrm{CI}=1.06$, 1.32) compared to men who reported never being drunk in the past year, and being drunk monthly or less vs. never was also associated with increased condomless sex $(\mathrm{aOR}=1.28, \quad 95 \% \quad \mathrm{CI}=1.10,1.49)$. Overall, men reporting ever being drunk vs. never drinkers in the past year had increased odds of reporting condomless sex with study partner $(\mathrm{aOR}=1.34,95 \% \mathrm{CI}=1.26,1.43$; not tabled). Men being HIV - at baseline (aOR $=1.43,95 \%$ $\mathrm{CI}=1.33,1.53$ ) was also associated with increased odds of reporting condomless sex during the study compared with HIV+ men at baseline, adjusting for man's heavy drinking, age, months since baseline, and years cohabiting.

Women who reported getting drunk less than monthly in the past year also had a higher odds of reporting condomless sex with study partner $(\mathrm{aOR}=1.39,95 \%$ $\mathrm{CI}=1.23,1.56)$ compared to women who reported never being drunk in the past year adjusting for woman's age, HIV status, months since baseline and years cohabiting. As in the bivariate analyses, reporting being drunk monthly or weekly was not associated with condomless sex (aOR for monthly vs. never $=1.10,95 \% \mathrm{CI}=0.91,1.33$; aOR for weekly vs. never $=1.05,95 \% \quad \mathrm{CI}=0.87,1.26)$. The finding that being drunk daily was protective $(\mathrm{aOR}=0.63)$ was likely due to small numbers in that category $(n=24$ women). Overall, women being drunk vs. never drinkers was associated with condomless sex in the past 3-months with study partner $(\mathrm{aOR}=1.20,95 \% \mathrm{CI}=1.09,1.31$; not tabled). The woman being HIV+ at baseline was associated with increased condomless sex during the study $(\mathrm{aOR}=1.45,95 \% \mathrm{CI}=1.35,1.56)$ compared to the woman being HIV - controlling for woman's age, months since baseline, woman's heavy drinking and years cohabiting (Table 4).

\section{Alcohol Association With Outside Sex Partners}

Men who reported being drunk daily or almost daily at baseline were more likely to report 1 or more outside sex partners during the study (aOR for drunk vs. never drunk $=1.68,95 \% \mathrm{CI}=1.41,2.01$ [not tabled]; aOR for being drunk daily or almost daily $=1.91(95 \% \mathrm{CI}=1.50$, 
Table 3 Baseline factors associated with women's and men's heavy drinking (reporting being drunk weekly or more frequently vs. drunk less than weekly or never in year prior to baseline) in the Zambia cohort study ( $\mathrm{n}=1929$ couples), 2002-2012

Crude prevalence OR $(95 \% \mathrm{CI})$

Outcome: Women's heavy drinking

Women age (per year increase)

Age disparity with male partner (per year increase)

Man HIV-/Woman HIV+

Men reported heavy drinking (weekly or daily vs. less than weekly or never)

Number of live children (per child increase)

Outcome: Men's heavy drinking

Men age (per year increase)

Age disparity with partner (per year increase)

Years cohabiting (per year increase)

Men illiterate in Nyanja

Women reported heavy drinking (weekly or daily vs. less than weekly or never)

Number of sex partners in past year (per partner increase)

Men self-reported STI in last year

$1.03(1.01,1.06)$
$0.95(0.92,0.99)$
$2.24(1.56,3.22)$
$2.65(1.86,3.78)$
$0.82(0.69,0.99)$

$0.98(0.97,0.99)$
$0.96(0.94,0.98)$
$0.99(0.98,0.99)$
$1.24(1.17,1.32)$
$1.63(1.36,1.94)$
$1.09(1.02,1.17)$
$1.22(1.00,1.48)$

$1.04(1.00,1.09)$

$0.94(0.88,1.01)$

$2.03(1.12,3.67)$

$3.93(1.94,7.17)$

$0.86(0.70,1.04)$

$1.00(0.98,1.01)$

$0.97(0.94,0.99)$

$1.00(0.98,1.02)$

$1.20(0.99,1.45)$

$1.63(1.35,1.96)$

$1.07(0.99,1.15)$

$1.22(0.99,1.15)$

STI sexually transmitted infection, $C I$ confidence interval, $O R$ odds ratio

Bold values $\mathrm{p}<0.05$

2.43); aOR for being drunk weekly vs. never $=1.32(95 \%$ $\mathrm{CI}=1.08,1.62)$; and aOR $2.03(95 \% \mathrm{CI}=1.57,2.62)$ for being drunk monthly vs. never), adjusting for age, years cohabiting, months since baseline and HIV status. Men being HIV - was also associated with having outside partners during the study $(\mathrm{aOR}=1.45,95 \% \mathrm{CI}=1.23$, 1.71) adjusting for age, months since baseline, years cohabiting, and man's heavy drinking.

Women who reported ever being drunk at baseline vs. never drinkers had increased odds of reporting 1 or more outside sex partners during the study compared to women who were never drunk $(\mathrm{aOR}=1.90,95 \% \mathrm{CI}=1.34,2.68$; not tabled), adjusted for women's age, HIV status, months since baseline and years cohabiting. Women reporting being drunk monthly vs. never was associated with outside partners $(\mathrm{aOR}=2.75,(95 \% \mathrm{CI}=1.56,4.75)$ (Table 4$)$.

\section{Alcohol Association With ART Initiation}

Overall, $17 \%$ of HIV infected individuals started ART during the study ( $\mathrm{n}=316$ couples). After restricting analyses to individuals in the cohort 2007 or later (when ART first became available in government clinics), women who were HIV+ and reported being drunk monthly or more frequently in the past year had decreased odds of initiating ART during the study (aOR $=0.83,95 \%$ $\mathrm{CI}=0.70,0.99$ ) adjusting for age, months since baseline and number of previous pregnancies, compared to women who reported never being drunk in the past year. For men, there was no association between delayed ART initiation and alcohol use (data not tabled).
Baseline Alcohol Use Association With Women's HIV Acquisition

There were 131 seroconversions in initially HIV- women. After controlling for woman's age, literacy, years cohabiting and previous pregnancies, men's heavy drinking was associated with trends of increased HIV transmission to their partners (adjusted hazard ratio [aHR] = drunk weekly or more frequently $=1.42,95 \% \mathrm{CI}=0.97,2.10$ ) compared to men who reported being drunk less than weekly or never in the past year. Women's reporting of being drunk weekly, daily or almost daily at baseline was marginally associated with increased HIV acquisition $(\mathrm{aHR}=3.71$, $95 \% \mathrm{CI}=0.90,15.25$ ), adjusting for age, literacy, years cohabiting and number of previous pregnancies compared to women who never reported being drunk in the past year. In both cases, the $95 \%$ CI included 1 (Table 5).

\section{Baseline Alcohol Use Association With Men's HIV Acquisition}

There were 137 seroconversions in initially HIV - men. Men reporting being drunk weekly, daily or almost daily at baseline was significantly associated with increased HIV acquisition $(\mathrm{aHR}=1.72,95 \% \mathrm{CI}=1.01,2.93)$ adjusting for men's age, literacy, years cohabiting, and male circumcision compared to men who drank less than weekly or never reported being drunk in the past year. Women's drinking was not associated with increased HIV transmission to male partners $(\mathrm{aHR}=1.70,95 \% \mathrm{CI}=0.42,6.93)$ (Table 5). 
Table 4 Association between alcohol consumption in previous year at baseline and condomless sex with main partner and $\geq 1$ outside partner in past 3 months during study stratified by gender

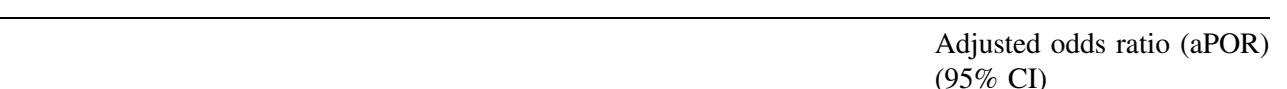
$(95 \% \mathrm{CI})$

Condomless sex in past 3 months and man drinking

Man drunk daily or almost daily vs. never

$1.18(1.06,1.32)$

Man drunk weekly vs. never

$0.98(0.90,1.06)$

Man drunk monthly vs. never

$0.93(0.82,1.05)$

Man drunk less than monthly vs. never

$1.28(1.10,1.49)$

Man's age (per year increase)

$0.99(0.99,1.00)$

Years cohabiting (per year increase)

$0.99(0.99,1.00)$

$\mathrm{M}-/ \mathrm{F}+$

$1.43(1.33,1.53)$

Months since baseline (per month increase)

$0.98(0.98,0.99)$

Condomless sex in past 3 months and woman drinking

Woman drunk daily or almost daily vs. never

$0.63(0.42,0.94)$

Woman drunk weekly vs. never

$1.05(0.87,1.26)$

Woman drunk monthly vs. never

$1.10(0.91,1.33)$

Woman drunk less than monthly vs. never

$1.39(1.23,1.56)$

Woman's age (per year increase)

$0.99(0.98,1.00)$

$0.99(0.99,1.00)$

Years cohabiting (per year increase)

$1.45(1.35,1.56)$

$\mathrm{M}-/ \mathrm{F}+$

Months since baseline (per month increase)

$0.98(0.98,0.99)$

$\geq 1$ outside partner in past 3 months and man drinking

Man drunk daily or almost daily vs. never

$1.91(1.50,2.43)$

Man drunk weekly vs. never

$1.32(1.08,1.62)$

Man drunk monthly vs. never

$2.03(1.57,2.62)$

Man drunk less than monthly vs. never

$0.85(0.56,1.29)$

Man age (per year increase)

$0.99(0.97,1.00)$

Years cohabiting (per year increase)

$1.00(0.98,1.02)$

$\mathrm{M}-/ \mathrm{F}+$

$1.45(1.23,1.71)$

Months since baseline (per month increase)

$0.98(0.98,0.99)$

$\geq 1$ outside partner in past 3 months and woman drinking

Woman drunk daily or almost daily vs. never

$1.42(0.35,5.79)$

Woman drunk weekly vs. never

$1.83(0.94,3.55)$

Woman drunk monthly vs. never

$2.75(1.56,4.75)$

Woman drunk less than monthly vs. never

$1.56(0.97,2.52)$

Woman age (per year increase)

$0.98(0.95,1.01)$

Years cohabiting (per year increase)

$1.01(0.98,1.04)$

$\mathrm{M}-/ \mathrm{F}+$

$1.32(0.97,1.80)$

Months since baseline (per month increase)

$1.01(1.00,1.01)$

$a O R$ Adjusted odds ratio, $C I$ confidence interval

Bold values $\mathrm{p}<0.05$

\section{Discussion}

This is the first study among HIV serodiscordant couples in Southern Africa to show how men's and women's alcohol consumption continues to affect high-risk sexual behaviors, HIV incidence and ART initiation after joint testing and counseling. In both $\mathrm{M}+\mathrm{F}-$ and $\mathrm{M}-\mathrm{F}+$ couples, men's and women's heavy drinking was correlated. Among both men and women, drunkenness was associated with increased reporting of condomless sex with the main partner as well as having outside sex partners. The risk of HIV acquisition was consistently higher in both men and women when either partner reported heavy drinking, though for some associations the $95 \%$ CI bounded 1. Finally, HIV+ women who reported being drunk weekly or more were less likely to initiate ART. 
Table 5 Time to seroconversion stratified by gender of seroconverter as estimated by Cox regression models

\begin{tabular}{|c|c|c|}
\hline & Crude HR $(95 \%$ CI $)$ & Adjusted HR $(95 \% \mathrm{CI})$ \\
\hline \multicolumn{3}{|c|}{ Model 1: Men heavy drinking and women's HIV acquisition $(\mathrm{n}=804 \mathrm{M}+\mathrm{F}-$ couples; $\mathrm{n}=131$ seroconversions $)$} \\
\hline Men reported being drunk less than weekly or never being drunk in past year & Ref & Ref \\
\hline Men reported being drunk weekly, daily or almost daily & $1.36(0.94,1.97)$ & $1.42(0.97,2.10)^{*}$ \\
\hline Women's age (per year increase) & $0.96(0.93,0.99) *$ & $0.96(0.93,0.99)^{* *}$ \\
\hline Woman illiterate & $0.84(0.57,1.23)$ & $0.66(0.39,1.14)$ \\
\hline Years cohabiting (per year increase) & $0.94(0.90,0.97)^{*}$ & $1.00(0.97,1.00)$ \\
\hline Number of previous pregnancies (per pregnancy increase) & $0.89(0.84,0.95)^{* *}$ & $0.95(0.88,1.03)$ \\
\hline \multicolumn{3}{|c|}{ Model 2: Women heavy drinking and women's HIV acquisition $(\mathrm{n}=804 \mathrm{M}+\mathrm{F}-$ couples; $\mathrm{n}=131$ seroconversions $)$} \\
\hline Women reported being drunk less than weekly or never drunk in past year & Ref & Ref \\
\hline Women reported being drunk weekly, daily or almost daily & $3.63(0.88,14.91)$ & $3.71(0.90,15.25)^{*}$ \\
\hline Women's age (per year increase) & $0.95(0.92,0.98)^{* *}$ & $0.98(0.95,1.01)$ \\
\hline Woman illiterate & $1.76(1.03,2.99) * *$ & $1.38(0.97,1.95)^{*}$ \\
\hline Years cohabiting (per year increase) & $0.94(0.90,0.97)^{* *}$ & $0.99(0.96,1.03)$ \\
\hline Number of previous pregnancies (per pregnancy increase) & $0.81(0.73,0.90) * *$ & $0.95(0.87,1.03)$ \\
\hline \multicolumn{3}{|c|}{ Model 3: Men heavy drinking and men's HIV acquisition ( $\mathrm{n}=1125 \mathrm{M}-\mathrm{F}+$ couples, $\mathrm{n}=137$ seroconversions $)$} \\
\hline Men reported being drunk less than weekly or never being drunk in past year & Ref & Ref \\
\hline Men reported being drunk weekly, daily or almost daily & $1.62(0.89,2.96)$ & $1.72(1.01,2.93)^{* *}$ \\
\hline Men’s age (per year increase) & $0.97(0.94,0.99)^{* * *}$ & $0.98(0.96,1.01)^{*}$ \\
\hline Men illiterate & $1.13(0.78,1.62)$ & $1.04(0.72,1.51)$ \\
\hline Male circumcised & $0.23(0.09,0.56)^{* *}$ & $0.23(0.09,0.57)^{* *}$ \\
\hline Years cohabiting (per year increase) & $0.95(0.91,0.99)^{* *}$ & $0.96(0.92,1.00)^{*}$ \\
\hline \multicolumn{3}{|c|}{ Model 4: Women heavy drinking and men's HIV acquisition ( $\mathrm{n}=1125 \mathrm{M}-\mathrm{F}+$ couples; $\mathrm{n}=137$ seroconversions $)$} \\
\hline Women reported being drunk less than weekly or never drunk in past year & Ref & Ref \\
\hline Women reported being drunk weekly, daily or almost daily & $1.23(0.30,5.01)$ & $1.70(0.42,6.93)$ \\
\hline Men’s age (per year increase) & $0.98(0.95,1.01)^{*}$ & $0.98(0.96,1.00)^{*}$ \\
\hline Men illiterate & $1.53(0.96,2.46)$ & $0.95(0.72,1.24)$ \\
\hline Male circumcised & $0.23(0.09,0.56)^{* *}$ & $0.46(0.28,0.76)^{* *}$ \\
\hline Years cohabiting (per year increase) & $0.95(0.91,0.99)^{* *}$ & $0.97(0.94,1.00)^{*}$ \\
\hline
\end{tabular}

$H R$ Hazard ratio

$* \mathrm{p}<0.10 ; * * \mathrm{p}<0.05$

Our study supports previous studies in which an individual's alcohol use and intoxication is associated with their and their partner's practice of sexual risk behaviors including concurrent or multiple sex partners and condomless sex $[5,7,9,10,20]$. Previous research has similarly demonstrated that HIV acquisition has been shown to increase when alcohol is consumed before sex [10]. Our results are unique because they measure the risk of condomless sex within $\mathrm{M}+\mathrm{F}-$ and $\mathrm{M}-\mathrm{F}+$ discordant couples associated with drinking in either partner, as well as the risk of outside partners among men and women reporting heavy drinking. This increase in exposures both within and outside the marriage results in both giving and getting HIV for both male to female and female to male transmission. Though drinking patterns were similar among HIV+ and HIV - men, HIV + women had increased odds of reporting heavy drinking compared with HIV- women. As most women learned of their serostatus after the time frame of reported alcohol use, this suggests that alcohol may have contributed to risk of HIV acquisition prior to CVCT. Women who seroconvert while pregnant or trying to conceive are also at-risk of transmitting HIV to their infants. After counseling, condomless sex was reported more frequently among $\mathrm{M}-\mathrm{F}+$ couples when adjusted for other variables.

Because alcohol is associated with negative health effects, including impaired inflammatory response, as well as poor treatment adherence [13], drinking raises concern about maintaining the wellbeing of HIV+ adults. Men and women who are heavy drinkers (defined as $\geq 5$ drinks on the same occasion on each of 5 or more days in the past 30-days), or who binge drink (defined as drinking 4 or more drinks for women and 5 or more drinks for men in one sitting), may also be at risk of rapid HIV progression [6]. We identified that HIV+ women in our study who reported heavy drinking at baseline had decreased odds of 
initiating ART during study follow-up. This may reflect the general dysfunction that heavy alcohol use can have on individuals' lifestyles-that they take less care of themselves and are less aware of their need for care and services. It may also reflect a divergence of resources from funds that could go to support transportation and other expenses related to ART (though ART is free in Zambia) to support alcohol consumption. HIV care providers must also consider how heavy alcohol use by women patients may affect their general health as well as HIV progression and encourage alcohol treatment and control if patients are to achieve better health. As delineated in the CDC couples' HIV counselling and testing guidelines, clients are advised that alcohol use may impair judgement and lead to exposure to HIV. Our program regularly sought out partners that could provide services that we could not, including treatment for alcoholism. Unfortunately, these services are usually small scale and localized, for example within a church or large scale employer.

\section{Limitations}

Our cohort was a select group attending clinic-based couple's HIV testing and counseling, and follow-up over time. These couples were either invited by an INA or INL in their respective community, heard about the service through word of mouth, or received another referral to the services. Thus all couples self-selected into couples' counseling and testing and into the cohort study. Among those who received invitations, differences between those who did seek CVCT and those that did not include inviting the couple vs. the individual, being socially acquainted (versus unknown to the couple) with the INA, being home during invitation versus elsewhere and easy invitation delivery versus difficult [14]. Despite similarities between demographics in the cohort and DHS data, the most important difference between the couples in this study and other discordant couples is that they are aware of their own and each-others' test results and have been counselled accordingly [14, 21]. Selection bias may also have affected the study as couples who stayed in the cohort may differ in terms of their health-seeking behavior, or other demographic or behavioral data, from similar couples who were not enrolled or were lost to follow-up, or separated [22]. A study from 2008 found that residence far from the clinic, younger age, and women's age at first intercourse $<17$ years were predictive of attrition in the same Zambian cohort. No income, $<2$ lifetime sex partners, no history of STI in women, and recent extramarital contact in their male partners predicted attrition in $\mathrm{F}+\mathrm{M}-$ couples [22]. At the beginning of this study, ART was not commonly available in Zambia. However, after 2007, ART became available in government clinics and ART-using couples were referred to these clinics and released from the cohort. Those eligible for ART had more advanced disease which may also affect the generalizability of results. Further, there may be a tendency to under-report alcohol use as well as risky sexual behaviors. This would be a non-differential misclassification, as it would not be associated with heavy alcohol use, and would under-estimate the true effect of alcohol on risky sexual behaviors. Data collection methods in this study were completed with nurse or counselors who were familiar with participants, which could cause social desirability bias. As a result, information bias due to exposure variables captured as self-reported is possible. In addition, alcohol use patterns were only collected at baseline, which prohibited us from analyzing alcohol consumption trends over time. However, since we see the association with baseline alcohol and risk behaviors, we consider this a useful measure. Recent studies have shown that drinking habits do not change much over time for the average person [23].

\section{Conclusions}

Our findings suggest that heavy alcohol use may act as a counter-factor in secondary HIV prevention - offsetting the prevention impact of counseling that couples may receive by care providers. HIV - partners in serodiscordant couples who consume alcohol frequently, or who have partners who do, enhance their risk of HIV acquisition. Given the association between heavy alcohol use and condomless sex, multiple sex partnerships, HIV acquisition, and less adoption of HIV treatment among women, serodiscordant couples should be screened for and counseled about alcohol consumption. The risk of heavy alcohol consumption needs to be managed by care providers who should ensure that those who are heavy drinkers access treatment and care for potential alcoholism and recognize the challenge of this for those living with other drinkers. By counseling couples together, and making them more aware that they may be at increased risk of transmitting or acquiring HIV when either partner consumes alcohol, the rate of HIV transmission among serodiscordant couples may decrease while general well-being may increase. More research is needed on how to address the risk of heavy alcohol use in African settings with high HIV prevalence.

Acknowledgements We would like to acknowledge the couples and staff in Zambia that made this study possible.The corresponding author had full access to all of the data in the study and takes responsibility for the integrity of the data and the accuracy of the data analysis.

Funding This study was supported by the National Institute of Child Health and Development (NICHD R01 HD40125); National Institute 
of Mental Health (NIMH R01 66767); the AIDS International Training and Research Program Fogarty International Center (D43 TW001042); the Emory Center for AIDS Research (P30 AI050409); National Institute of Allergy and Infectious Diseases (NIAID R01 AI51231; NIAID R01 AI040951; NIAID R01 AI023980; NIAID R01 AI64060; NIAID R37 AI51231); the US Centers for Disease Control and Prevention (5U2GPS000758); and the International AIDS Vaccine Initiative. This study was made possible by the generous support of the American people through the United States Agency for International Development (USAID). The contents are the responsibility of the International AIDS Vaccine Initiative and do not necessarily reflect the views of USAID or the United States Government. The funders had no role in study design, data collection and analysis, decision to publish, or preparation of the manuscript.

\section{Compliance with Ethical Standards}

Conflict of interest D. Joseph Davey, W. Kilembe, K. M. Wall, N. Htee Khu, I. Brill, B. Vwalika, J. Mulenga, A. Tichacek, M. Javanbakht, W. Scott Comulada, S. Allen, P. Gorbach declare that they have no conflict of interest.

Ethical approval All procedures performed in studies involving human participants were in accordance with the ethical standards of the institutional and/or national research committee and with the 1964 Helsinki declaration and its later amendments or comparable ethical standards.

Informed consent Informed consent was obtained from all individual participants included in the study.

\section{References}

1. UNAIDS. UNAIDS Global Report, 2013. Accessed January 10, 2017 http://www.unaidsorg/en/resources/campaigns/globalreport 2013/globalreport.

2. Allen S, Meinzen-Derr J, Kautzman M, Zulu I, Trask S, Fideli U, et al. Sexual behavior of HIV discordant couples after HIV counseling and testing. AIDS. 2003;17(5):733-40.

3. Chomba E, Allen S, Kanweka W, Tichacek A, Cox G, Shutes E, et al. Evolution of couples' voluntary counseling and testing for HIV in Lusaka, Zambia. J Acquir Immune Defic Syndr. 2008; 47(1):108-15.

4. Matovu JK. Preventing HIV transmission in married and cohabiting HIV-discordant couples in sub-Saharan Africa through combination prevention. Curr HIV Res. 2010;8(6):430-40.

5. Mah TL, Halperin DT. Concurrent sexual partnerships and the HIV epidemics in Africa: evidence to move forward. AIDS Behav. 2010;14(1):11-6 dicussion 34-7.

6. Bagby GJ, Stoltz DA, Zhang P, Kolls JK, Brown J, Bohm RP Jr, et al. The effect of chronic binge ethanol consumption on the primary stage of SIV infection in rhesus macaques. Alcohol Clin Exp Res. 2003;27(3):495-502.

7. Coldiron ME, Stephenson R, Chomba E, Vwalika C, Karita E, Kayitenkore K, et al. The relationship between alcohol consumption and unprotected sex among known HIV-discordant couples in Rwanda and Zambia. AIDS Behav. 2008;12(4): 594-603.
8. Hahn JA, Woolf-King SE, Muyindike W. Adding fuel to the fire: alcohol's effect on the HIV epidemic in Sub-Saharan Africa. Curr HIV/AIDS Rep. 2011;8(3):172-80.

9. Ruzagira E, Wandiembe S, Abaasa A, Bwanika AN, Bahemuka $\mathrm{U}$, Amornkul P, et al. HIV incidence and risk factors for acquisition in HIV discordant couples in Masaka, Uganda: an HIV vaccine preparedness study. PLoS ONE. 2011;6(8):e24037.

10. Scott-Sheldon LA, Carey KB, Cunningham K, Johnson BT, Carey MP, Team MR. Alcohol use predicts sexual decisionmaking: a systematic review and meta-analysis of the experimental literature. AIDS Behav. 2016;20(Suppl 1):S19-39.

11. Anglemyer A, Rutherford GW, Baggaley RC, Egger M, Siegfried $\mathrm{N}$. Antiretroviral therapy for prevention of HIV transmission in HIV-discordant couples. Cochrane Database Syst Rev. 2011; 8:CD009153.

12. O'Connell R, Chishinga N, Kinyanda E, Patel V, Ayles H, Weiss $\mathrm{HA}$, et al. Prevalence and correlates of alcohol dependence disorder among TB and HIV infected patients in Zambia. PLoS ONE. 2013;8(9):e74406.

13. McCance-Katz EF, Lum PJ, Beatty G, Gruber VA, Peters M, Rainey PM. Untreated HIV infection is associated with higher blood alcohol levels. J Acquir Immune Defic Syndr. 2012;60(3):282-8.

14. Wall KM, Kilembe W, Nizam A, Vwalika C, Kautzman M, Chomba E, et al. Promotion of couples' voluntary HIV counselling and testing in Lusaka, Zambia by influence network leaders and agents. BMJ Open. 2012;2(5):e001171.

15. Stephenson R, Shutes E, McKenna S, Allen S, Brill I, Kancheya $\mathrm{N}$, et al. The impact of project closure on HIV incidence and mortality in a cohort of couples in Lusaka, Zambia. AIDS Care. 2008;20(6):683-91.

16. Trask SA, Derdeyn CA, Fideli U, Chen Y, Meleth S, Kasolo F, et al. Molecular epidemiology of human immunodeficiency virus type 1 transmission in a heterosexual cohort of discordant couples in Zambia. J Virol. 2002;76(1):397-405.

17. Boeras DI, Luisi N, Karita E, McKinney S, Sharkey T, Keeling $\mathrm{M}$, et al. Indeterminate and discrepant rapid HIV test results in couples' HIV testing and counselling centres in Africa. J Int AIDS Soc. 2011;14:18.

18. Conigrave KM, Hall WD, Saunders JB. The AUDIT questionnaire: choosing a cut-off score. Alcohol use disorder identification test. Addiction. 1995;90(10):1349-56.

19. Schoenfeld DA. Sample-size formula for the proportional-hazards regression model. Biometrics. 1983;39(2):499-503.

20. Kinuthia J, Kiarie JN, Farquhar C, Richardson B, Nduati R, Mbori-Ngacha D, et al. Cofactors for HIV-1 incidence during pregnancy and postpartum period. Curr HIV Res. 2010;8(7): $510-4$.

21. Stephenson R, Barker J, Cramer R, Hall MA, Karita E, Chomba E, et al. The demographic profile of sero-discordant couples enrolled in clinical research in Rwanda and Zambia. AIDS Care. 2008;20(3):395-405.

22. Kempf MC, Allen S, Zulu I, Kancheya N, Stephenson R, Brill I, et al. Enrollment and retention of HIV discordant couples in Lusaka, Zambia. J Acquir Immune Defic Syndr. 2008;47(1): 116-25.

23. Martinez P, Roislien J, Naidoo N, Clausen T. Alcohol abstinence and drinking among African women: data from the World Health Surveys. BMC Public Health. 2011;11:160. 